\title{
REVIEWS
}

\section{The Quality of Life and Psychological, Social and Cognitive Functioning of Patients with Acromegaly}

${ }^{1}$ Division of Consulting Psychiatry and Neurobiological Research, Department of Psychiatry, Wroclaw Medical University, Poland

${ }^{2}$ Department of Endocrinology, Diabetology and Isotope Therapy, Wroclaw Medical University, Poland

A - research concept and design; $\mathbf{B}$ - collection and/or assembly of data; C - data analysis and interpretation;

$\mathbf{D}$ - writing the article; $\mathbf{E}$ - critical revision of the article; $\mathbf{F}$ - final approval of article; $\mathbf{G}$ - other

\begin{abstract}
Acromegaly is a rare and chronic disease, most often caused by a pituitary adenoma. Excessive secretion of the growth hormone $(\mathrm{GH})$ leads to hepatic secretion of insulin-like growth factor-1 (IGF-1), which in turn causes characteristic changes in the patient's appearance, many skeletal deformities and metabolic disorders. In addition to somatic symptoms, acromegalic patients demonstrate psychosocial and personality deficits, as well as common co-occurrence of mental disorders. There are few studies investigating acromegaly in Poland. In recent years, the concept of quality of life has become fundamental to understanding health problems. Studies dealing with acromegaly likewise tend to include assessments of quality of life of patients suffering from this endocrinopathy (Adv Clin Exp Med 2015, 24, 1, 167-172).
\end{abstract}

Key words: acromegaly, GH, quality of life, mental disorder, cognitive disorder.

Acromegaly is a rare and chronic illness characterized by changes in appearance, skeletal deformities and metabolic disorders. Due to the fact that this disease is a statistically abnormal phenomenon, it has been the subject of interest for centuries. Kałużny and Bolanowski pointed out the multiplicity of historical and scientific sources concerning people who may have suffered from acromegaly, from the Hebrew Bible to very recent studies [1]. The first medical description of people suffering from acromegaly dates to 1864 and was created by Andrea Vergi. More than 20 years later, in 1886, Pierre Marie introduced the term acromegaly (gr. akron - limb, gr. megas - large) after conducting two autopsies. Later researchers focused on exploring the causes of acromegaly and its impact on the human body.

In $95 \%$ of cases, acromegaly is the result of excessive secretion of the growth hormone $(\mathrm{GH})$ by a hormonally active adenoma of the anterior lobe of the pituitary gland. This in turn leads to excessive secretion of insulin-like growth factor-1 (IGF-1), a peripheral mediator responsible for the majority of the symptoms of acromegaly. The vast majority of pituitary adenomas are benign. Cancers occur rarely and their malignancy is determined by the presence of distant metastases. Ectopic production of the growth hormone is uncommon. To date, its production has been reported in pancreatic tumors, ovarian cancer and the non-Hodgkin's lymphoma [2-4]. There are individual cases of acromegaly presented in the literature in which the disease was caused by an overdose of growth hormone therapy in children lacking the hormone [5], or in athletes using $\mathrm{GH}$ as a performance-enhancing drug [6]. The onset of acromegaly symptoms is conditioned by a high dosage of the hormone over a period of several years. The changes in physical appearance result from bone and soft tissue proliferation in the distal extremities, the jaw, tongue, lips, nose and the frontal eminence [7-9]. An excess of the growth hormone disturbs the functioning of the cardiovascular, musculoskeletal, respiratory, nervous and digestive systems [10]. 
The incidence of acromegaly is estimated at 3 to 4 new cases per million population per year, depending on the source, whereas the prevalence of the disease in the general population is estimated at 40 to 70 per million [7-9]. However, because of the difficulty in identifying the initial symptoms of the disease, the epidemiology of acromegaly may be much higher. Referring to Belgian and German studies, Chanson indicates a greater prevalence of the disease than previously described, estimating it to be $100-130$ cases per million people. This indicates a twofold increase in the incidence of the disease in the population in comparison with earlier data [11]. At the same time, he stresses the need for verification of these findings.

The delay in identifying acromegaly is on average 5 to 10 years [12], although there are individual reports of faster detection of the disease, within 2 to 3 years of the occurrence of the first symptoms [11]. Additionally, it has been noticed that this delay is two times longer in patients aged 50 and above compared to patients below 30 years of age (12.3 years vs 6 years, respectively) [13]. The difficulty in identifying the disease may be associated with the non-specificity of the initial symptoms, such as increased sweating, minor soft tissue swelling, decreased physical activity and increased fatigue. Changes in appearance may be unnoticeable to the patient as well as to his/her immediate environment. Patients frequently attribute these changes to "ugly aging". Typical symptoms of the disease include enlarged hands and feet, prognathism (excessive protrusion of the mandible or maxilla), enlargement of the supraorbital ridges, enlargement of the tongue, nose and thickening of the lips. Acromegaly leads to characteristic changes in the patient's appearance, allowing a correct diagnosis [14]. At present, the diagnosis of acromegaly is made 10 years from the onset of the first symptoms.

Acromegaly involves changes not only in the patient's physical appearance. Metabolic abnormalities, such as an impaired glucose tolerance, diabetes, an abnormal lipid profile and hypertension are much more serious consequences of the disease and can lead to cardiac hypertrophy, heart failure and a higher incidence of ischemic heart disease. Cardiovascular complications are the leading cause of death in patients with acromegaly $[15,16]$. Changes in the appearance, movement dysfunction, frequently coexisting gonadotropin or adrenocorticotropic deficiency as well as dysfunction of bodily systems (including the circulatory, respiratory, digestive and neurological systems) all decrease the patients' quality of life and may affect their performance of daily activities, particularly in the advanced, active stages of the disease.
The aim of acromegaly treatment is to normalize GH secretion, which can lead to a restored life expectancy in the patient population [12]. Three treatment options can be used: surgical, pharmacological or radiation therapy. The most radical - yet optimal - treatment option is the surgical removal of the tumor, preferably through the sphenoid sinus approach, in order to maintain the other functions of the pituitary. Pharmacological and radiotherapy are complementary treatment options used in case of contraindications to surgery or the ineffectiveness of surgical treatment.

This paper aims to illustrate a significant relationship between acromegaly and the psychological, social and cognitive aspects of the patient's everyday life.

\section{Coexistence of Mental Disorders and Acromegaly}

It should be stressed that psychiatric disorders co-occur with acromegaly more frequently than "in other" somatic dysfunctions. However, there is little data in the literature dealing with this matter. Recent studies indicate a greater risk of developing affective disorders, particularly depression, in patients with acromegaly than in patients with other chronic diseases [17]. However, the role of excessive growth hormone secretion in the development of depression remains unclear. The possibility of developing psychotic disorders in patients with acromegaly has also been emphasized [10], and there are individual reports in the literature on this subject [18], based primarily on case reports. The psychotic symptoms may, however, result from previously used pharmacotherapy in the disease, rather than arising from the disease itself. One such example is the case of a patient diagnosed with acromegaly and treated with bromocriptine. [19]. This person developed a series of symptoms of paranoid schizophrenia, which receded within a week after discontinuing the drug and administering thioridazin, a classical antipsychotic drug (which is no longer available in Poland). There are no reports describing the co-occurrence of acromegaly with other psychiatric disorders, such as anxiety or manic depressive disorders. Furthermore, there is no available data indicating specific personality disorders in patients with acromegaly. There is also no evidence in the literature of intellectual dysfunction in this group of patients.

Nevertheless, there are some data indicating an association of the disease with personality changes before, in the course of, and after treatment. In their articles, Furman and Ezzat as well as Mattoo et al. underlines the importance of the 
duration of treatment in acromegaly, which can contribute to the development of symptoms similar to post-traumatic stress disorder (PTSD), such as limited recall in memory, detachment, sleep disorders, problems with concentration and social isolation $[10,20]$.

\section{The Psychological, Social and Cognitive Functioning of Patients with Acromegaly}

Despite little available data on the coexistence of clinical mental disorders and acromegaly, there are studies focusing on the psychological, social and cognitive functioning of this group of patients. Researchers began to explore this area in depth at the end of the $20^{\text {th }}$ century. However, there seems to be little interest in Poland in the effects of acromegaly on the psychosocial functioning of the patients.

There is one study in the literature carried out by a team from Poznan focusing on how the use of an analogue of somatostatin in acromegaly affects the somatic and psychological functioning of patients. It was found that the most significant changes resulting from the use of the drug were associated with relief of headache and arthritis pain, as well as a decrease in the patient's physical restrictions. In addition, treatment with somatostatin analogues led to subjective reports from the patients of an improvement in their interpersonal relationships as well as in their cognitive functions [21].

Sievers et al. conducted a longitudinal study that compared 70 patients diagnosed with acromegaly, 58 patients with a nonfunctioning pituitary adenoma and a group of 140 healthy subjects [22]. The results show higher levels of conformity and neuroticism, as well as higher levels of anticipated worries, pessimism, fatigue and asthenia in the acromegalic patients compared to healthy subjects. However, these variables do not differentiate subjects with acromegaly from those with a nonfunctioning pituitary adenoma. Acromegalic subjects do, however, exhibit specific characteristics, such as a decreased tendency to seek new experiences and low spontaneity. In contrast to previous reports, Ruchala et al. emphasized that acromegalic subjects had a high level of satisfaction with life and efficacy, which are an important factor in coping with the disease; the results were linked to treatment based on somatostatin analogues [21]. At the same time, the subjects of an Indian study showed a high level of negative emotions, such as anger, anxiety and sadness [20].

Moreover, the effect of the disease on the cognitive function of patients has been pointed out in the literature [23-25]. A study using event related potentials (ERPs) conducted by Tanriverdi et al. provides electrophysiological evidence for cognitive dysfunction among people with excessive growth hormone secretion [23]. The researchers underlined the need for further studies and clinical application of the obtained results.

A study by Leon-Carrion et al. conducted on 16 patients with diagnosed acromegaly and 16 healthy subjects as a control group confirms the hypothesis of cognitive impairment among people suffering from acromegaly [24]. The researchers developed a comparative analysis focusing on neurocognitive areas of human functioning, such as executive functioning, verbal memory, visual memory and concentration. The results indicate short and long-term memory loss among the subjects as well as a reduction in activity in certain

Table 1. Symptoms of patients suffering from acromegaly before being diagnosed; between confirmed diagnosis and surgery; after surgical treatment

\begin{tabular}{|l|l|l|}
\hline Before diagnosis & After diagnosis/before surgery & After surgery \\
\hline Increased irritability & relief & PTSD \\
Increased anxiety & impatience & sadness \\
Emotional liability & psychological strain & anger \\
Feeling uncertain & guilt & fatigue \\
Anxiety & social withdrawal & sleep disorders \\
Sadness & body image distortion & body image distortion \\
Sleep disorders & fear of brain damage & competence disorders \\
Difficulty concentrating & fear of death & social withdrawal \\
High level of stress & fear of medical procedures & limited interest in daily activities \\
Drop in self-esteem & anger & impaired function of short-term \\
Sense of a loss of competence & helplessness & memory \\
Loss of control & sadness & denial of illness \\
& sleep disorders & avoidance of medical staff \\
& restlessness & \\
\hline
\end{tabular}


areas of the brain. The authors argue that an excess of GH and IGF-1, its peripheral mediator, can be of significant importance in these findings.

Table 1 presents information illustrating the association between acromegaly and psychosocial functioning (adapted from Furman and Ezzat, 1998) [10].

\section{Acromegaly and the Quality of Life}

In recent years, the quality of life (QoL) has become a fundamental concept in terms of the health-disease continuum. According to Webb and Badia, it is the patient who is the expert and judge in this area, because it is his/her feelings, thoughts and everyday activities that are taken into consideration. Individuals' goals, expectations, living standards and the social and cultural context of their life play a key role in their quality of life [26]. In the literature, a relationship between acromegaly and a sense of a decreased quality of life is emphasized [26-35], primarily linked to locomotor system dysfunction [36]. Joint pain has a significant negative impact on the patients' quality of life. To date there is no effective treatment for the disabling persisting joint pains associated with acromegaly. Replacement surgery and the use of analgesics can currently be proposed to the patients. Biermesz et al. showed that the presence of joint problems is associated with reduced scores on several different QoL questionnaires. Acromegalic patients have a high prevalence of joint-related comorbidity and - very importantly - joint complaints contributed to a reduction in these patients' perceived quality of life [37].

Wassenaar et al. found that as many as $90 \%$ of acromegalic subjects report musculoskeletal pain, which correlates negatively with their perceived quality of life [38]. Acromegaly patients have high spine, knee and hip pain scores, which limit their physical functioning and psychological well-being and is associated with impaired quality of life scores. However, there are factors other than locomotor dysfunction which are also important. Body image and the side effects of radiotherapy can affect psychological aspects of the subjects' life, particularly their stress level, and, consequently, their perceived quality of life [39]. The study that van der Klaauw et al. conducted on patients diagnosed with acromegaly who had been subjected to radiotherapy indicates that this treatment option increases social isolation, leads to a decrease in activity and motivation, higher scores on the depression scale and an increase in perceived anxiety [40].
In 1999, Webb and Badia developed a questionnaire to examine the perception of quality of life in acromegaly (AcroQoL) [26]. Their research emphasizes that the quality of life is correlated with variables such as age, the duration of the disease, radiotherapy, the presence of other symptoms, disease activity and gender, as women seemingly report a lower quality of life [26].

According to the latest consensus concerning the diagnosis, treatment and monitoring of acromegaly, a quality of life questionnaire should be routinely used when dealing with acromegalic patients [41]. This is due to the fact that, apart from the somatic symptoms of the disease, there are numerous other dysfunctions in people suffering from acromegaly. Pereira et al. found that compared to subjects with other pituitary tumors, schwannomas or chronic pain, patients with acromegaly had the most negative perception of their illness. The studied group of patients displayed cognitive impairment and personality disorders, and a further $36 \%$ were additionally diagnosed with anxiety disorders and depression. These variations occurred in patients with the active form of the disease as well as those treated successfully and with long-lasting remissions. Like previous researchers, Pereira et al. postulated that the dysfunctions are most probably a consequence of irreversible alterations to the central nervous system (CNS) occurring as a result of excessive levels of GH. Therefore, many physicians propose that the assessment of the efficacy of treatment should be based not only on biochemical and image normalization, but also on assessments of the subject's mental health and personality profile [41].

However, there are inconsistencies in results regarding the effect of disease activity (increased $\mathrm{GH}$ and IGF-1 levels) on the perception of the quality of life. A study by Matta et al. on 96 patients with diagnosed acromegaly shows no difference in the perception of the quality of life between the group with and without hormonal control [34]. On the other hand, research conducted by Trepp et al. on 33 treated and 22 untreated patients with inactive pituitary tumors indicates that IGF-1 levels have a statistically significant effect on the quality of life [35]. Patients who did not undergo pharmacological therapy had a significantly lower perception of their quality of life.

The discrepancies in results concerning the effect of hormonal levels on the quality of life make this a key area for future research. At the same time, the importance of the patient's perceived quality of life needs to be highlighted, because the patients may perceive themselves and their lives as "different" despite medical control of hormonal levels [26]. 
Introducing an interdisciplinary approach to the treatment of patients with acromegaly is fundamental, as is the introduction of psychological intervention in order to improve their quality of life. The data presented in this article also draw attention to the nature of these patients' psychosocial functioning, and to the co-occurrence of psychiatric and endocrine disorders among these patients. The scarcity of studies relating to this matter, particularly in Polish medical and psychological literature, has also been highlighted.

\section{References}

[1] Kałużny M, Bolanowski M: Akromegalia - od mitów do faktów. Endokrynol Pol 2008, 59, 242-244.

[2] Beuschlein F, Strasburger CJ, Siegerstetter V, Moradpour D, Lichter P, Bidlingmaier M, Blum HE, Reincke M: Acromegaly caused by secretion of growth hormone by a non-Hodgkin's lymphoma. N Engl J Med 2000, 342, 1871-1876.

[3] Boix E, Pico A, Pinedo R, Aranda I, Kovacs K: Ectopic growth hormone-releasing hormone secretion by thymic carcinoid tumour. Clin Endocrinol (Oxf) 2002, 57, 131-134.

[4] Melmed S, Ezrin C, Kovacs K, Goodmann RS, Frohman LA: Acromegaly due to secretion of growth hormone by an ectopic pancreatic islet - cell tumor. N Engl J Med 1985, 312, 9-17.

[5] Karges B, Pfaffle R, Boehm BO, Karges W: Acromegaly induced by growth hormone replacement therapy. Horm Res 2004, 61, 165-169.

[6] Macintyre JG: Growth hormone and athletes. Sport Med 1987, 4, 129-142.

[7] Ben-Shlomo A, Melmed S: Acromegaly. Endocrinol Metab Clin N Am 2008, 37, 101-122.

[8] Chanson P, Salenave S: Acromegaly. Orphanet Journal of Rare Diseases 2008, 3, 17.

[9] Zaleska-Kręcicka M, Zatoński T, Bolanowski M, Zatońska K: ENT disorders in acromegalic patients. Adv Clin Exp Med 2006, 15, 549-551.

[10] Furman K, Ezzat S: Psychological features of acromegaly. Psychoter Psychosom 1998, 67, 147-153.

[11] Chanson P, Salenave S, Kamenicky P, Cazabat L, Young J: Acromegaly. Best Pract Res Clin Endocrinol Metab 2009, 23, 555-574.

[12] Holdaway IM, Rajasoorya RC, Gamble GD: Factors influencing mortality in acromegaly. J Clin Endocrinol Metab 2004, 89, 667-674.

[13] Nabarro JD: Acromegaly. Clin Endocrinol (Oxf) 1987, 26, 481-512.

[14] Ezzat S, Forster MJ, Berchtold P, Redelmeier DA, Boerlin V, Harris AG: Acromegaly. Clinical and biochemical features in 500 patients. Medicine (Baltimore) 1994, 73, 233-240.

[15] Fatti LM, Scacchi M, Pincelli AI, Lavezzi E, Cavagnini F: Prevalence and pathogenesis of sleep apnea and lung disease in acromegaly. Pituitary 2001, 4, 259-262.

[16] Orme SM, McNally RJ, Cartwright RA, Belchetz PE: Mortality and cancer incidence in acromegaly: a retrospective cohort study. J Clin Endocrinol Metab 1998, 83, 2730-2734.

[17] Sievers C, Dimopoulou C, Pfister H, Lieb R, Steffin B, Roemmler J, Schopohl J, Mueller M, Schneider HJ, Ising M, Wittchen HU, Stalla GK: Prevalence of mental disorders in acromegaly: a cross-sectional study in 81 acromegalic patients. Clin Endocrinol 2009, 71, 691-701.

[18] Hach B: An unusual psychopathologic case history in a patient with acromegaly. Nervenarzt 1976, 47, 456-459.

[19] Le Feuvre CM, Isaacs AJ, Franks OS: Bromocriptine-induced psychosis in acromegaly. Br Med J (Clin Res Ed) $1982,285,1315$.

[20] Mattoo SK, Bhansali AK, Gupta N, Grover S, Malhotra R: Psychosocial morbidity in acromegaly: a study from India. Endocr 2008, 34, 17-22.

[21] Ruchala M, Stangierska I, Gurgul E, Stangierski A, Fajfer J, Sowinski J: The effect of octreotide treatment on somatic and psychological symptoms of acromegaly. Neuro Endocrinol Lett 2010, 3, 265-269.

[22] Sievers C, Ising M, Pfister H, Dimopoulou C, Schneider HJ, Roemmler J, Schopohl J, Stalla GK: Personality in patients with pituitary adenomas is characterized by increased anxiety-related traits: comparison of 70 acromegalic patients with patients with non-functioning pituitary adenomas and age- and gender-matched controls. Eur J Endocrinol 2009, 160, 367-373.

[23] Tanriverdi F, Yapislar H, Karaca Z, Unluhizarci K, Suer C, Kelestimur F: Evaluation of cognitive performance by using P300 auditory event related potentials (ERPs) in patients with growth hormone (GH) deficiency and acromegaly. Growth Hormone \& IGF Research 2009, 19, 24-30.

[24] Leon-Carrion J, Martin-Rodriguez JF, Madrazo-Atutxa A, Soto-Moreno A, Venegas-Mareno E, Torres-Vela E, Benito-Lopez P, Galvez MA, Tinahones FJ, Leal-Cerro A: Evidence of cognitive and neurophysiological impairment in patients with untreated naive acromegaly. J Clin Endocrinol Metab 2010, 95, 4367-4379.

[25] Sievers C, Sämann PG, Pfister H, Dimopoulou C, Czisch M, Roemmler J, Schopohl J, Stalla GK, Zihl J: Cognitive function in acromegaly: description and brain volumetric correlates. Pituitary 2012, 350-357.

[26] Webb SM, Badia X: Quality of life in growth hormone deficiency and acromegaly. Endocrinol Metab Clin N Am 2007, 36, 221-232.

[27] Webb SM: Quality of Life in Acromegaly. Neuroendocrinology 2006, 83, 224-229.

[28] Badia X, Webb SM, Prieto L, Lara N: Acromegaly quality of life questionnaire (AcroQoL). Health Qual Life Outcomes 2004, 2, 13. 
[29] Biermasz NR, van Thiel SW, Pepeira AM, Hoftijzer HC, van Hemert AM, Smit JWA, Romijn JA, Roelfsema F: Decreased quality of life in patients with acromegaly despite long-term cure of growth hormone excess. J Clin Endocrinol Metab 2004, 5369-5376.

[30] Wexler T, Gunnell L, Omer Z, Kuhlthau K, Beauregard C, Graham G, Utz AL, Biller B., Nachtigall L., Loeffler J, Swearingen B, Klibanski A, Miller KK: Growth hormone deficiency is associated with decreased quality of life in patients with prior acromegaly. J Clin Endocrinol Metab 2009, 94, 2471-2477.

[31] Sonino N, Fava GA: Psychological aspects of endocrine disease. Clin Endocrinol 1998, 49, 1-7.

[32] Ben-Shlomo A, Sheppard MC, Stephens JM, Pulgar S, Melmed S: Clinical, quality of life, and economic value of acromegaly disease control. Pituitary 2011, 14, 284-294.

[33] Pantanetti P, Sanino N, Arnaldi G, Boscaro M: Self image and quality of life in acromegaly. Pituitary 2002, 5, 17-19.

[34] Matta MP, Couture E, Cazals L, Vezzosi D, Bennet A, Caron P: Impaired quality of life of patients with acromegaly: control of GH/IGF-I excess improves psychological subscale appearance. Eur J Endocrinol 2008, 158, 305-310.

[35] Trepp R, Everts R, Stettler C, Fischli S, Allemann S, Webb SM, Christ ER: Assessment of quality of life in patients with uncontrolled vs. controlled acromegaly using the acromegaly quality of life questionnaire (AcroQoL). Clin Endocrinol 2005, 63, 103-110.

[36] Biermesz NR, Pereira AM, Smit JW, Romijn JA, Roelfsema F: Morbidity after long-term remission for acromegaly: persisting joint-related complaints cause reduced quality of life. J Clin Endocrinol Metab 2005 May, 90, 2731-2739.

[37] Miller A, Doll H, David J, Wass J: Impact of musculoskeletal disease on quality of life in long-standing acromegaly. Eur J Endocrinol 2008, 158, 587-593.

[38] Wassenaar MJ, Biermasz NR, Kloppenburg M, van der Klaauw AA, Tiemensma J, Smit JW, Pereira AM, Roelfsema F, Kroon HM, Romijn JA: Clinical osteoarthritis predicts physical and psychological QoL in acromegaly patients. Growth Horm IGF Res 2010, 20, 226-233.

[39] Melmed S, Casanueva FF, Klibanski A, Bronstein MD, Chanson P, Lamberts SW, Strasburger CJ, Wass J AH, Giustina A: A consensus on the diagnosis and the treatment of acromegaly. Pituitary 2013, 16, 294-302.

[40] Van der Klaauw A, Biermasz NR, Hoftizjer C, Periera AM, Romijn JA: Previous radiotherapy negatively influences quality of life during 4 years of follow - up in patients cured from acromegaly. Clin Endocrinol 2008, 69, 123-128.

[41] Pereira AM, Tiemensma J, Romijn JA, Biermasz NR: Cognitive impairment and psychopathology in patients with pituitary diseases. Neth J Med 2012, 70, 255-260.

\section{Address for correspondence:}

Dorota Szcześniak

Department of Psychiatry

Wroclaw Medical University

Wybrzeże Pasteura 10

50-367 Wrocław

Poland

Tel.: +48 717841628

E-mail: deren.dorota@gmail.com

Conflict of interest: None declared

Received: 18.12.2013

Revised: 31.05.2014

Accepted: 12.01.2015 